\title{
Nucleosomal and Supranucleosomal Organization of Transcriptionally Inactive rDNA Circles in Dytiscus Oocytes
}

\author{
Ulrich Scheer ${ }^{1}$ and Hanswalter Zentgraf ${ }^{2}$ \\ ${ }^{1}$ Division of Membrane Biology and Biochemistry, Institute of Experimental Pathology, \\ and ${ }^{2}$ Institute of Virus Research, German Cancer Research Center, D-6900 Heidelberg, \\ Federal Republic of Germany
}

\begin{abstract}
Oocytes of the water beetle, Dytiscus marginalis, contain large amounts of rDNA most of which is present in the form of rings containing one or several pre-rRNA genes. Electron microscopy of spread preparations of vitellogenic oocytes has shown that the rDNA is extended in chromatin rings with transcribed pre-rRNA genes and is not packed into nucleosomes (Trendelenburg etal., 1976). When similar preparations are made from previtellogenic ooytes in which a large proportion of the nucleolar chromatin is transcriptionally inactive, a different morphological form of this chromatin is recognized. In contrast to the transcribed chromatin rings the inactive nucleolar chromatin circles show the characteristic beaded configuration, indicative of nucleosomal packing. Nucleosomal packing is also indicated by the comparison of the lengths of these chromatin rings with both isolated rDNA circles and transcribed chromatin rings. In addition, these inactive nucleofilaments often appear to be compacted into globular higher order structures of diameters from 21 to $34 \mathrm{~nm}$, each composed of an aggregate of 6-9 nucleosomes. While the estimated reduction of the overall length of rDNA, as seen in our preparations, is, on the average, only 2.2-2.4 fold in the nucleosomal state it is $10-13$ fold when supranucleosomal globules are present. These data show that the extrachromosomal rDNA of these oocytes goes through a cycle of condensation and extension, as a function of the specific transcriptional activity, and that the beaded state described here is exclusively found in the non-transcribed state.
\end{abstract}

\section{Introduction}

The amplified nucleolar DNA (rDNA) in the oocyte of the water beetle Dytiscus marginalis consists of numerous extrachromosomal circular molecules that contain variable numbers of pre-rRNA genes plus their adjacent spacer regions. 
As a consequence, the rDNA circles as well as the transcribed nucleolar chromatin rings of this cell occur in size classes containing one repeating unit or multiples thereof, with some remarkable heterogeneity of spacer lengths (Gall and Rochaix, 1974; Trendelenburg, 1974; Trendelenburg etal., 1976, 1977). We have previously shown that the axial lengths of the transcribed chromatin circles are identical to the contour lengths of the corresponding isolated rDNA circles (Trendelenburg etal., 1976; Franke etal., 1978a). This shows that under the conditions used for the electron microscopic spread preparation not only the transcribed portions of the rDNA but also apparently non-transcribed spacer regions are extended and excludes a nucleosomal compaction of the nucleolar chromatin (Franke etal., 1976; Trendelenburg etal., 1976; Franke etal., 1978a, b; for definition of nucleosomes see Elgin and Weintraub, 1975; Kornberg, 1977; Oudet etal., 1978; Klug, 1978).

On the other hand, it has recently been shown that in inactive stages of pre-rRNA genes in amphibian oogenesis the chromatin axes assume a nucleosomal organization (Scheer et al., 1976; Scheer, 1978). A similar abservation has been made with drug-induced inactivation of nucleolar chromatin (Scheer et al., 1975; Scheer, 1978). In such situations, however, it has not been possible, due to the absence of transcriptional complexes that serve as markers of rDNA sequence arrangement, to demonstrate a foreshortening of the rDNA. Assuming that similar structural changes take place during activation and inactivation of the nucleolar chromatin rings of Dytiscus oocytes, it should be possible to see variations in their contour lenghts, concomitant with the appearance of nucleosome-sized granules.

This 'paper describes the morphology of transcriptionally inactive rings of amplified nucleolar chromatin of Dytiscus oocytes and shows that inactive rDNA is not only compacted into nucleosomes but also into supranucleosomal higher order globules.

\section{Materials and Methods}

1. Animals. Dytiscus marginalis females were collected in ponds in the surroundings of Heidelberg during spring time. They were used immediately or were kept for one night in large water tanks at about $18^{\circ} \mathrm{C}$. Their ovaries contained all size classes of oocytes, from the very small previtellogenic oocytes up to mature oocytes about $7 \mathrm{~mm}$ long.

2. Purification and Isolation of Amplified rDNA. Per experiment the ovaries from two beetles were freed from all large $(>1 \mathrm{~mm})$ oocytes and were then immediately transferred into lysis medium (50 mM Tris- $\mathrm{HCl}, \mathrm{pH} 8.4,20 \mathrm{mM}$ EDTA, $1 \%$ Sarkosyl NL-97), containing $0.5 \mathrm{mg} / \mathrm{ml}$ pre-digested proteinase K (Merck, Darmstadt, Germany). After $2 \mathrm{~h}$ at $37^{\circ} \mathrm{C}$ pre-digested pronase (Calbiochem, San Diego, California, USA) was added to a final concentration of $0.5 \mathrm{mg} / \mathrm{ml}$, and the solution was incubated under gentle shaking for additional $6 \mathrm{hrs}$ at $37^{\circ} \mathrm{C}$. Solid $\mathrm{CsCl}$ was then added to an initial density of about $1.71 \mathrm{~g} / \mathrm{cm}^{3}$, and the DNA was centrifuged to equilibrium as described by Gall and Rochaix (1974). The rDNA-containing heavy peak or shoulder with a mean density of about $1.715 \mathrm{~g} / \mathrm{cm}^{3}$ was collected and precipitated by adding 3 vol. ice-cold $70 \%$ ethanol.

3. Electron Microscopy of Isolated rDNA. The ethanol-precipitated DNA was centrifuged, and the pellet was dissolved in $10 \mathrm{mM}$ Tris- $\mathrm{HCl}, \mathrm{pH} 7.2,1 \mathrm{mM}$ EDTA. The DNA molecules were spread by the cytochrome $\mathrm{c}$ droplet diffusion method (Lang and Mitani, 1970; cf. also Trendelenburg etal., 1976). 
4. Electron Microscopy of rDNA-containing Chromatin. An ovariole was placed in " 5:1-medium" $(0.1 \mathrm{M} \mathrm{KCl}$ and $0.1 \mathrm{M} \mathrm{NaCl}$ in a $5: 1$ ratio) buffered with $5 \mathrm{mM}$ Tris to $\mathrm{pH} 7.2$. Nuclei were manually isolated under a dissecting microscope from translucent, previtellogenic oocytes (oocyte diameter $0.2 \mathrm{~mm}$, nuclear diameter $0.1 \mathrm{~mm}$ ). In some experiments, nuclei with diameters ranging from $0.2-0.3 \mathrm{~mm}$ were isolated from early vitellogenic oocytes (oocytes with longer axes ranging from $0.4-0.8 \mathrm{~mm}$ ). The nuclei were washed in " $\mathrm{pH} 9$ water" (ca. $0.1 \mathrm{mM}$ sodium borate buffer, pH 9.0; Merck, Darmstadt) and were then immediately transferred into a drop of the same solution placed on a siliconized glass slide at about $10^{\circ} \mathrm{C}$ (in a Petri dish surrounded by crushed ice). If necessary, the nuclei were punctured with a fine needle, and the nuclear contents were allowed to disperse for 10-30 min. The chromatin material was then centrifuged onto a freshly glowdischarged carbon-coated grid according to the procedure of Miller (Miller and Bakken, 1972; cf. Trendelenburg, 1974; Trendelenburg etal., 1976, 1977). After positive staining with ethanolic phosphotungstic acid solution the grids were rotary shadowed with platinum/palladium $(80: 20)$ at an angle of about $8^{\circ} \mathrm{C}$. Electron micrographs were taken with a Zeiss EM 10 electron microscope. The magnification was calibrated with a grating replica. Prints were projected onto a digitizer tablet under exactly determined magnifications, and the contour lengths of rings of DNA or chromatin were determined with the analyzing system MOP-AM-01 (Kontron Messgeräte, Eching bei München, Germany).

\section{Results}

DNA extracted from ovaries of Dytiscus separates into two components with different buoyant densities when analyzed in a $\mathrm{CsCl}$ gradient. The heavier component is enriched in circular rDNA molecules of various lengths. (cf. Gall and Rochaix, 1974; Trendelenburg etal., 1976, 1978). Examples of such rings are presented in Figure 1. An analysis of the contour lengths of the smaller rDNA circles (up to $20 \mu \mathrm{m}$ ) of the sample used in this study has shown that most of them fall into two discrete size classes with mean values of 7.7 and $15.1 \mu \mathrm{m}$ (see Fig. 4a), in agreement with our earlier determinations (Trendelenburg etal., 1976, 1978). Larger circles (e.g., Fig. 1c) most probably represent higher multiples of these size classes but have not been included in the evaluation presented below since they show an increasing length heterogeneity, perhaps reflecting the variations of spacer lengths (See Trendelenburg etal., 1976).

In spread preparations of nucleolar chromatin isolated from growing, vitellogenic oocytes transcriptionally active chromatin rings of variable sizes are found (for a detailed analysis and documentation cf. Trendelenburg, 1974; Trendelenburg etal., 1976, 1977). The smallest chromatin circles with a length of about $7 \mu \mathrm{m}$ consist of one "repeating unit" (i.e., one transcribed portion, the "matrix unit", plus the adjacent, apparently non-transcribed "spacer" region). Another size class with a mean peak length of about $14-15 \mu \mathrm{m}$ contains two repeating units, etc. (cf. Trendelenburg et al., 1976). From these observations we conclude that rDNA circles such as those presented in Figure 1 represent molecules containing one pre-rRNA gene (Fig. 1a), two genes (Fig. 1 b), and three genes (Fig. 1c), respectively.

In order to study the organization and the contour lengths of chromatin circles not engaged in transcription we have isolated and spread the nuclear chromatin from small, previtellogenic oocytes. Depending on the specific oocyte stage, a variable proportion of the amplified nucleolar chromatin circles shows no transcriptional activity as recognized by the absence of transcriptional com- 

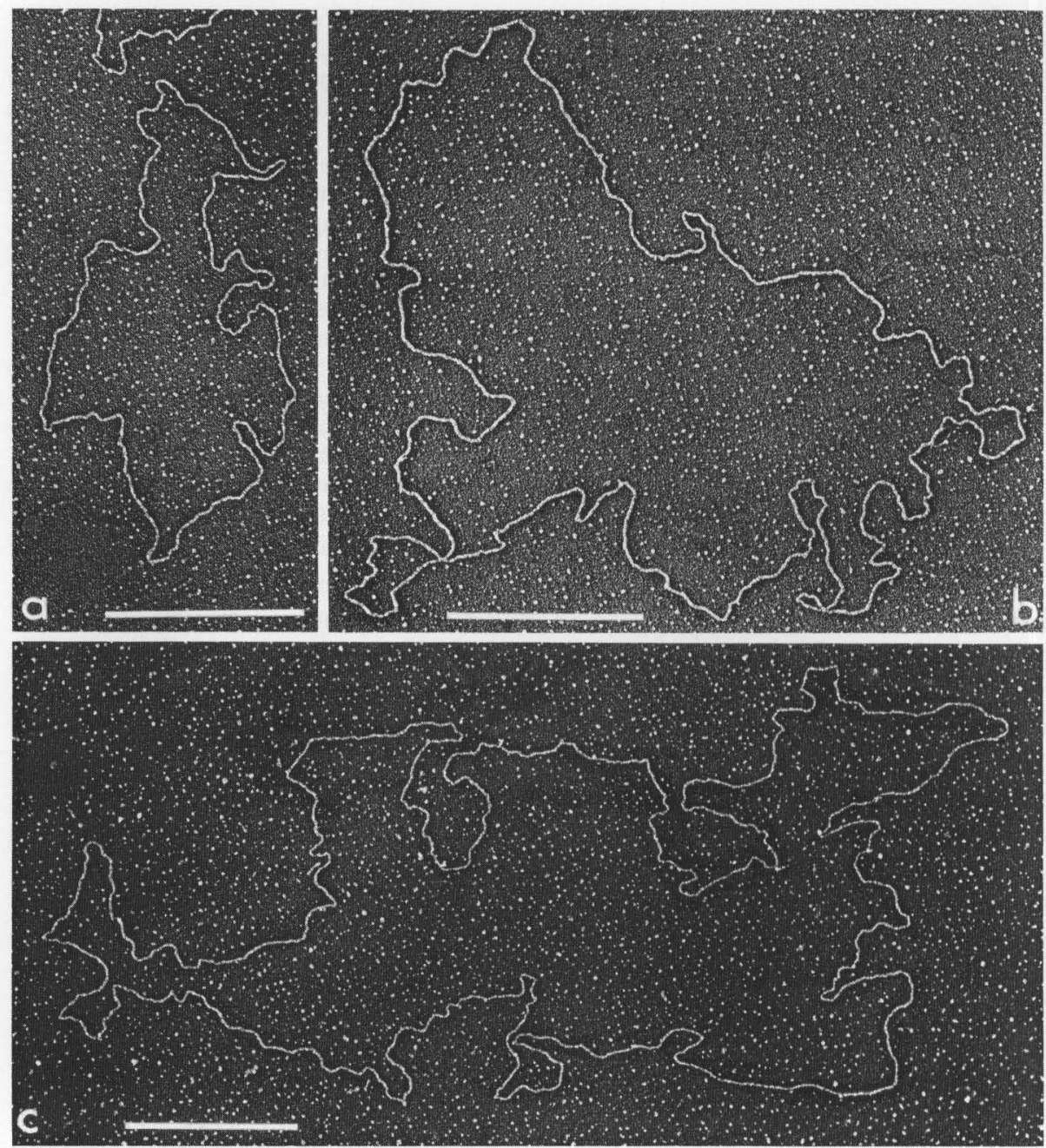

Fig. 1a-c. Electron micrographs of cytochrome c-DNA spread preparations showing typical examples of circular molecules of different size classes of rDNA, isolated from ovaries of Dytiscus marginalis. The specific contour lengths of the molecules shown are $8.6 \mu \mathrm{m}$ (a smallest ring class observed, i.e., "one pre-rRNA gene ring"), $17.2 \mu \mathrm{m}$ (b probably containing two pre-rRNA genes), and $26 \mu \mathrm{m}$ (c probably containing three pre-rRNA genes). Bars indicate $1 \mu \mathrm{m}$

plexes (lateral ribonucleoprotein fibrils). The fact that in early oogenesis of Dytiscus marginalis the pre-rRNA genes are largely inactive but are transcribed later in vitellogenic oocytes is comparable to the process of pre-rRNA gene activation occuring in small oocytes of various species of vertebrates (e.g. Ford, 1972; Scheer et al., 1976; Denis, 1977). In nuclei of Dytiscus oocytes with diameters of $0.2 \mathrm{~mm}$ or less apparently all pre-rRNA genes are inactive, and the nucleolar chromatin circles reveal a characteristic "beads-on-a-string" appearance (Fig. 2). The diameters of these globular particles, which are in close 

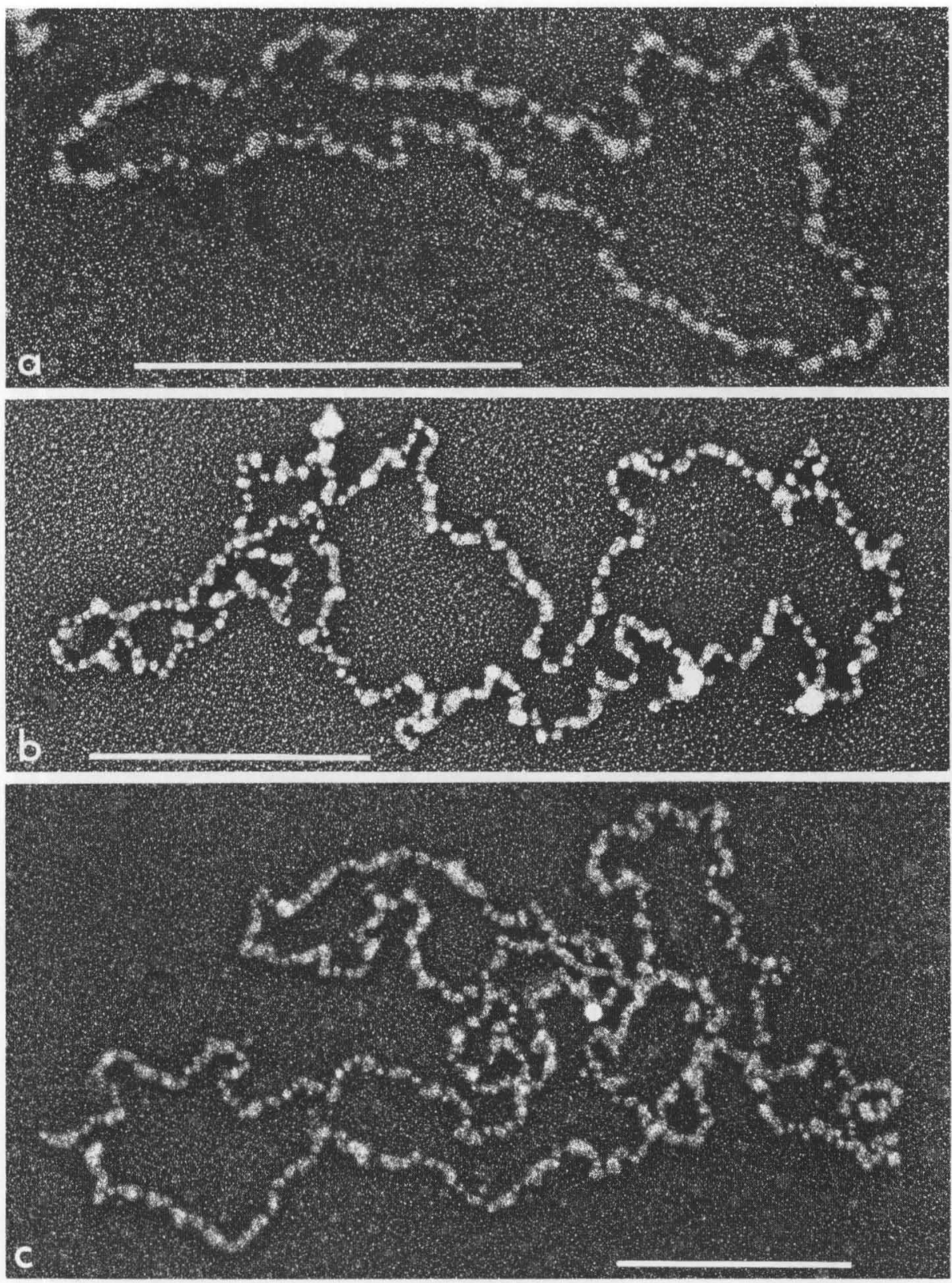

Fig. 2 a-c. Spread preparations (modified procedure of Miller and coworkers; cf. Miller and Bakken, 1972) of transcriptionally inactive rings of rDNA-containing chromatin prepared from previtellogenic oocytes. Note the beaded aspect of the chromatin indicative of nucleosomal organization. The contour lengths of the rings shown are $3.35 \mu \mathrm{m}$ (a representative of the smallest size class observed), $6.72 \mu \mathrm{m}$ (b representative of class II rings, probably containing two pre-rRNA genes), and $11.55 \mu \mathrm{m}$ (c probably containing three pre-rRNA genes). Bars indicate $0.5 \mu \mathrm{m}$ 


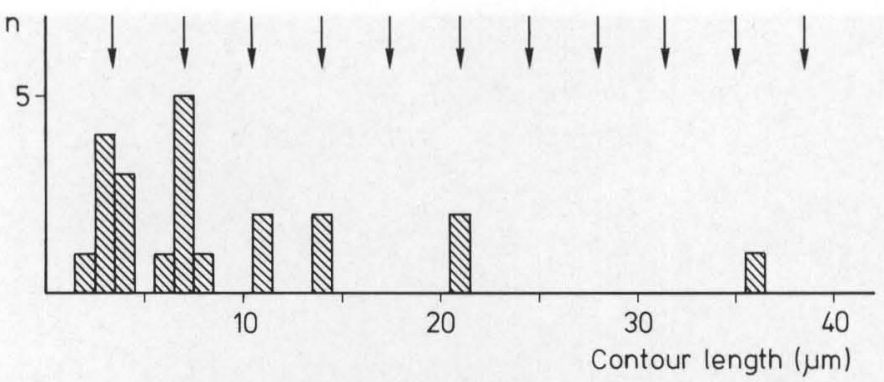

Fig. 3. Histogram showing the length distribution of transcriptionally inactive rDNA-containing chromatin rings (see Fig. 2). The chromatin circles fall into various size classes. There is an indication of the preference of multiples (arrows) of a basic size class (about $3.5 \mu \mathrm{m}$; denoted by the left arrow)

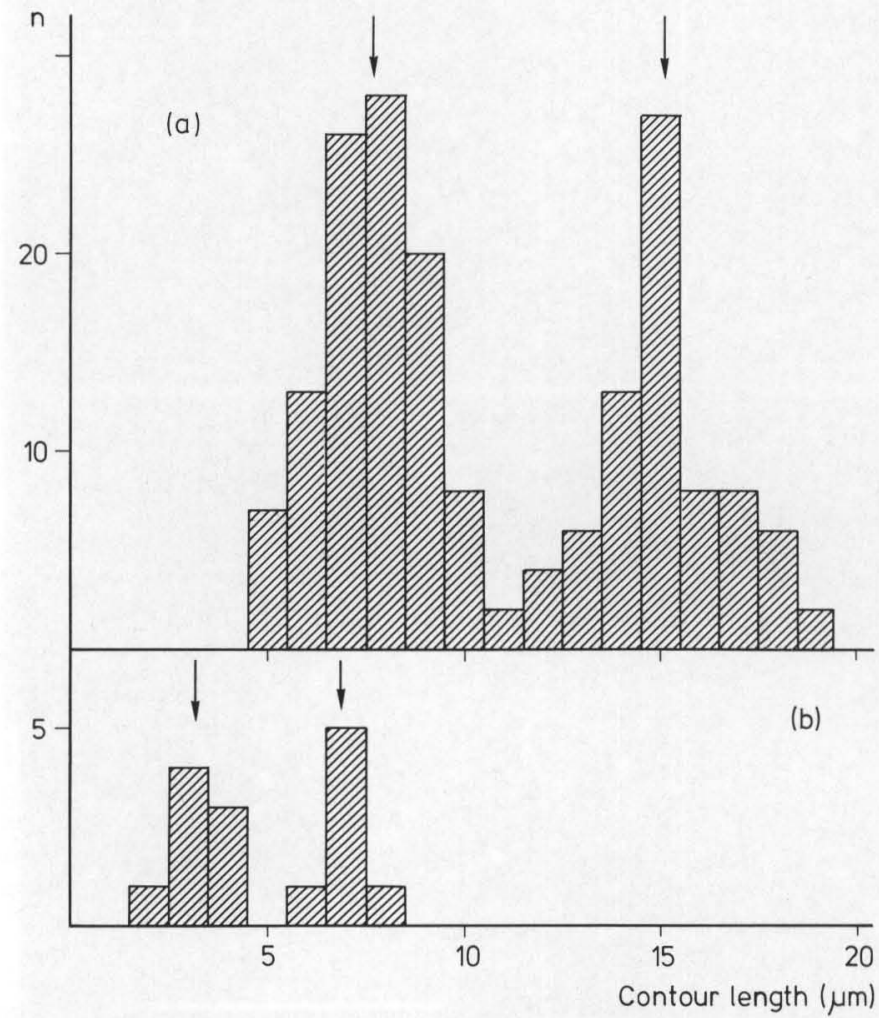

Fig. 4 a and b. Comparison of the contour lengths of isolated rDNA circles (a cf. Fig. 1) and transcriptionally inactive chromatin rings with a beaded appearance (b cf. Fig. 2). In the histograms shown here only the two smallest size classes of DNA and chromatin circles, respectively, have been included, showing mean peak values of 7.7 and $15.1 \mu \mathrm{m}$ (arrows in a), and 3.16 and $6.85 \mu \mathrm{m}$ (arrows in b) 

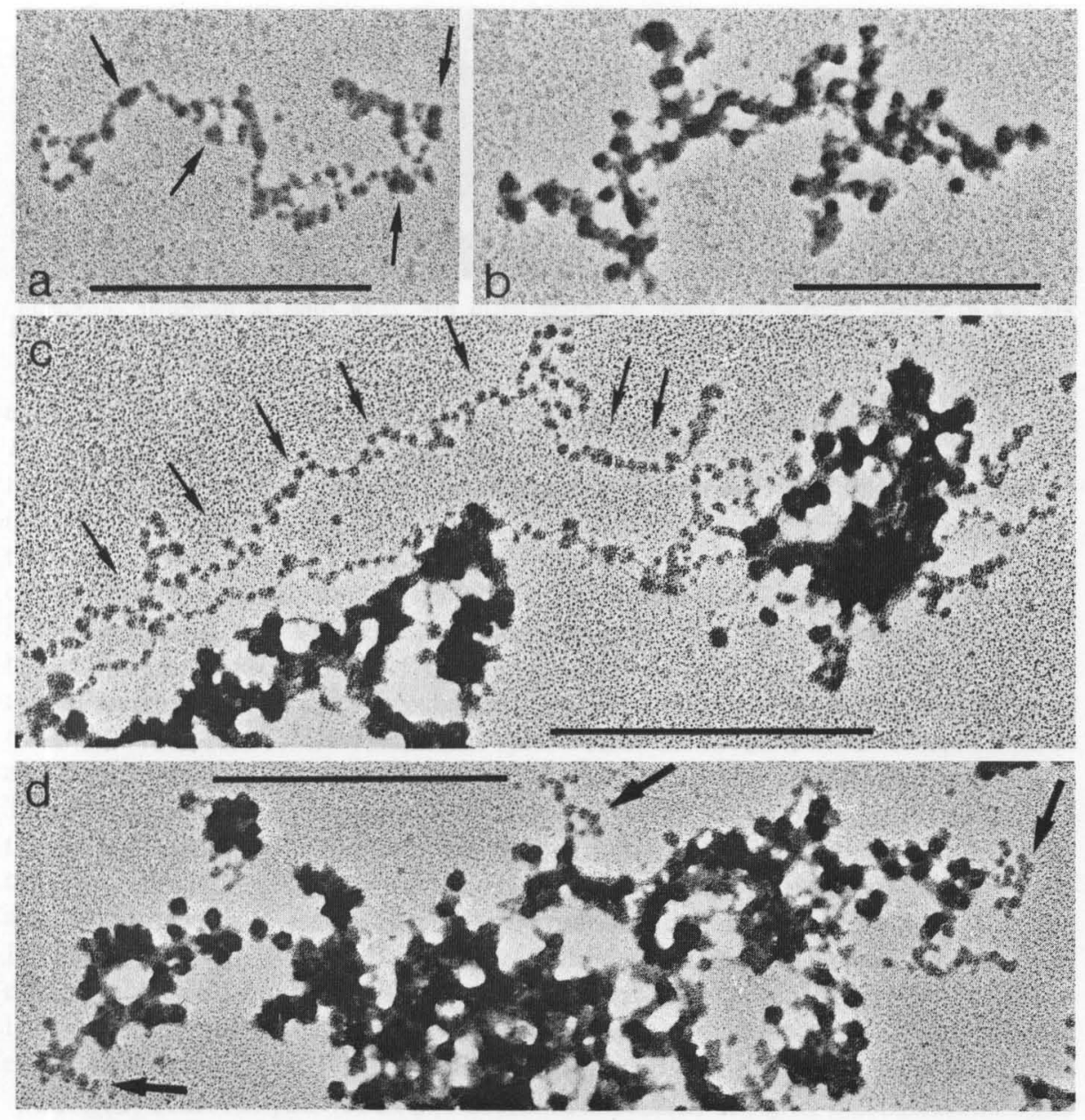

Fig. 5a-d. Spread preparation (same procedure as in Fig. 2) of inactive nucleolar chromatin, revealing package into globular structures of higher order. The ring shown in a shows a beaded nucleosome-like organization and, in addition, some larger supranucleosomal globular particles (a, arrows). Sometimes extrachromosomal chromatin material is found in such preparations which appears completely compacted into such large units (b). The simultaneous occurrence of nucleosomal (arrows in c) and supranucleosomal structures is demonstrated in $\mathbf{c}$ and $\mathbf{d}$. Some situations suggest that individual large globular units have unravelled into clusters of 6-9 nucleosomes (arrows in d). Bars indicate $0.5 \mu \mathrm{m}$

contact or are separated by variable distances, range from 10 to $13 \mathrm{~mm}$, i.e., the typical sizes of nucleosomes prepared under similar conditions (cf. Franke et al., 1976, 1978b; Oudet et al., 1975, 1978; Scheer, 1978). A histogram of the contour lengths of such inactive chromatin circles with a nucleosomal organization is presented in Figure 3. Again, the distribution indicates the occurrence of discrete peaks of size classes, with a predominant basic unit of about $3.5 \mu \mathrm{m}$ (Fig. 3). The largest ring traced has a length of $36.2 \mu \mathrm{m}$ (Fig. 3). 

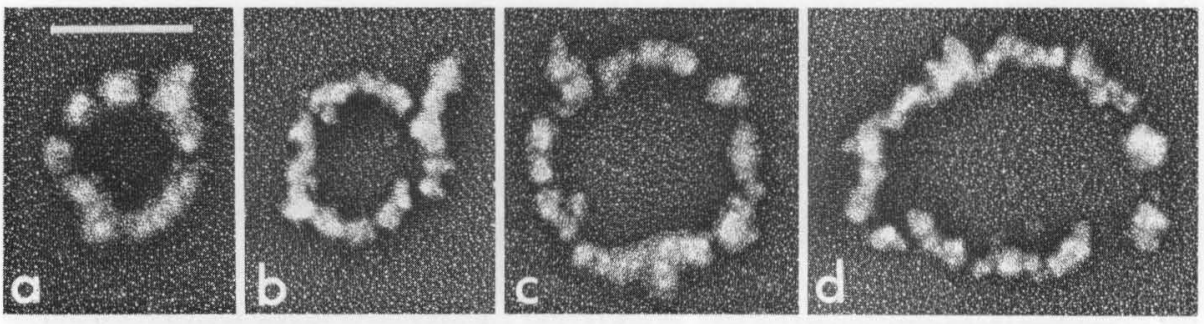

Fig. 6 a-d. Spread preparations (same procedure as in Fig. 2) of rings of nucleolar chromatin compacted into supranucleosomal globular units. These higher order structures $(21-34 \mathrm{~nm}$ in diameter) are significantly larger than nucleosomes (10-13 nm under the conditions used here.) The smallest circles detected probably contain one pre-rRNA gene and consist of 10-20 globules with total contour lengths from $0.67 \mu \mathrm{m}$ (a) to $0.85 \mu \mathrm{m}$ (b); the next larger class size of rings, probably containing two pre-rRNA genes, shows 2647 globules and greater contour lengths. Two examples are presented in $\mathbf{c}(1.15 \mu \mathrm{m}$ contour length) and $\mathbf{d}(1.27 \mu \mathrm{m})$. Bar indicates $0.2 \mu \mathrm{m}$.

Comparison of the lengths of the two smallest classes of inactive chromatin rings with the corresponding size classes of rDNA circles show a striking size reduction (Fig. 4). The mean contour length of the smallest chromatin rings (Fig. $4 \mathrm{~b}$ ) is $3.16 \mu \mathrm{m}$, that of the next larger size class $6.85 \mu \mathrm{m}$. Thus, the resulting factor of size reduction, relative to the fully extended state of rDNA, is 2.2-2.4.

The spacing of the nucleosome-sized particles in the inactive nucleolar chromatin shows considerable variation, probably reflecting various degrees of local rearrangement during the preparation. Regions of close spacing are seen next to regions with much greater internucleosomal spacings (Fig. 2). The average number of nucleosomes per micrometer of chromatin axis in our preparations is fairly constant at 39 , a figure which is slightly higher than corresponding values reported for transcriptionally inactive chromatin of other insect cells (28-34, in Oncopeltus fasciatus and Drosophila melanogaster; Foe et al., 1976; McKnight and Miller, 1977; Laird et al., 1976). On the average, the smallest class of chromatin rings consists of $80-159$ (mean: 123) nucleosomes (Fig. 2a), the next larger ring class of 214-321 (mean: 274) nucleosomes (Fig. 2b).

In spread preparations of oocyte nuclei characterized by the predominance of completely inactive pre-rRNA genes we have consistently found chromatin circles which are highly twisted and coiled (Fig. 5a). In addition, the nucleosomal particles often seem to be aggregated into much larger globular structures of diameters ranging from 21 to $34 \mathrm{~nm}$ (Fig. $5 \mathrm{a}, \mathrm{b}$ ). The proportion of the chromatin material compacted into such higher order granular structures has been found to be variable and seems to reflect the specific state of decondensation. In very early stages of oogenesis a large proportion of the nucleolar chromatin is highly condensed and appears, in the spread preparations described here, as thick fibers or rows of supranucleosomal particles (Fig. 5c,d). Only occasionally, individual higher order units seem to have unravelled into clusters of 6-9 nucleosomes (Fig. 5d). Although most of this highly compacted, inactive nucleolar chromatin is aggregated into large, dense masses we sometimes have seen apparently relaxed chromatin circles (Fig. 6). Such rings appear as fibers with a more or less uniform, $25 \mathrm{~nm}$ thick width and usually can be resolved 
into distinct supranucleosomal units (Fig. 6). The smallest rings of this highly compacted form consist of 10-20 supranucleosomal units, with a total circle size of $0.67-0.85 \mu \mathrm{m}$ (Fig. 6a, b). The next larger ring size class contains 24-47 large globules and shows contour lengths from 1.15 to $1.27 \mu \mathrm{m}$ (Fig. 6c, d). This suggests that here the rDNA is foreshortened by a factor of 10-13, compared to its fully extended state. Furthermore, it can be estimated that each supranucleosomal unit contains, on the average, 7-8 nucleosomes.

\section{Discussion}

The results of this study, together with those presented earlier (Trendelenburg et al., 1976, 1977), show that the circles of rDNA-containing chromatin of Dytiscus oocytes undergo profound structural changes as a function of their transcriptional activity. In agreement with previous studies in other cell systems (e.g. Franke et al., 1976, 1978 a, b; Scheer et al., 1977; Scheer, 1978) we conclude that fully transcribed chromatin is organized in a non-nucleosomal extended configuration whereas inactive chromatin is compacted into nucleosomes. The identification of the nucleosomal nature of units of package of inactive chromatin has so far been based on the disappearance of the "beads-on-a-string-pattern" upon treatment with detergents resulting in the dissociation of histones from the DNA (Scheer, 1978). Here we show that the formation of nucleosomes also results in an apparent reduction of the length of the specific DNA molecule. The resulting ratio of condensation (Length of DNA/length of chromatin in the beaded state) is 2.2 to 2.4 , a figure comparable to that determined in the chromatin-like nucleoprotein complexes of simian virus (SV40), polyoma and papilloma virus spread under similar conditions (2.5 to 3.5; e.g., Griffith 1975; Cremisi et al., 1976; Bellard et al., 1976; Favre et al., 1977). A similar compaction of the circular mitochondrial DNA of Xenopus oocytes into granular DNA-protein complexes has also been reported (condensation ratio 3.4; Pinon et al., 1978).

Since the rDNA circles are packed into defined numbers of nucleosomes we can calculate that each "nucleosomal equivalent" (i.e., nucleosomal granule plus one adjacent internucleosomal "linker" filament) contains on the average 184 nucleotide pairs. This value agrees well with the nucleosome DNA content of about 200 nucleotide pairs determined by nuclease digestion experiments (for references see Oudet et al., 1978; Li, 1977; Kornberg, 1977; Klug, 1978).

Above this compaction into a chain of nucleosomes ("nucleofilament" according to Klug, 1978) inactive rDNA chromatin is further condensed, at higher order level, into supranucleosomal globular units with diameters ranging from 21-34 nm. As a consequence the contour length of a "one gene" containing ring of rDNA is reduced from $7.7 \mu \mathrm{m}$ to about $0.7 \mu \mathrm{m}$ and appears as an annular chain composed of about 16 large, densely spaced globular units. Similarly-sized globular units have been described in highly condensed chromatin of various somatic cells, especially in ultrathin sections through the peripheral chromatin layers (cf. Franke and Scheer, 1974; Zentgraf et al., 1975; Franke et al., 1978a, b) and in spread preparations of chromatin (Kiryanov et al., 1976; Franke et al., 1976, 1978b; Renz et al., 1977; Hozier et al., 1977; Sträting et al., 
1978; Popenko and Vengerov, 1978). Moreover, when SV40 chromatin is prepared under conditions assumed to preserve the native state of the nucleoprotein complex it appears as a compact globular aggregate composed of about four supranucleosomal globules (Keller et al., 1978; Müller et al., 1978; Zentgraf et al., 1978). Therefore, such higher order units seem to be of widespread occurrence and might represent a general mode of nucleofilament package. Our present results also allow the estimation that one such unit is composed of 6-9 nucleosomes. Similar values have been determined by other authors using different methods (Renz et al., 1977; Hozier et al., 1977; Strätling et al., 1978). How this chain of higher order globules relates to the concept of a uniformly 20-30 nm thick solenoidal chromatin fiber (Finch and Klug, 1976; Worcel and Benyajati, 1977; Klug, 1978) remains to be clarified.

In summary, our observations demonstrate that during oogenesis of Dytiscus the extrachromosomal rDNA of the oocytes goes through a cycle of condensation and extension as a function of the specific transcriptional activity. The condensed inactive state is characterized, in spread preparations, by the appearance of nucleosomes and supranucleosomal globules and is clearly distinguished from transcribed chromatin which is associated with nascent ribonucleoprotein fibrils and appears in an extended, non-nucleosomal configuration (see Trendelenburg et al., 1976; Franke et al., 1976, 1978a, b). A similar cycle of morphological changes has been described in amphibian oogenesis (Scheer et al., 1976; Scheer, 1978) in which, however, a precise calculation of the compaction of the rDNA could not be performed, due to the infrequency of small circles of rDNA in diplotene stages (cf. Scheer et al., 1976; Trendelenburg et al., 1978).

The mechanisms involved in the structural changes of chromatin are totally unknown. However, recent studies of amphibian oogenesis and embryogenesis of the milkweed bug, Oncopeltus fasciatus, have indicated that the transition of rDNA-containing chromatin from the condensed to the extended state and vice versa is not an immediate consequence of the transcriptional process but apparently can be dissociated from it since defined "non-beaded" chromatin regions have been observed in stages preceding or following transcription of rDNA (Foe, 1978; Scheer, 1978). The rDNA circles abundant in Dytiscus oocytes seem to represent an especially suitable system for future studies of the relationship between chromatin organization and transcriptional activity.

Acknowledgements. We thank Dr. W.W. Franke for his help and criticism during the preparation of the manuscript. The work has been supported by the Deutsche Forschungsgemeinschaft (grant Sche 157/3).

\section{References}

Bellard, M., Oudet, P., Germond, J.-E., Chambon, P.: Subunit structure of Simian virus-40 minichromosome, Europ. J. Biochem. 70, 543-553 (1976)

Cremisi, C., Pignatti, P.F., Croissant, O., Yaniv, M.: Chromatin-like structures in Polyoma virus and Simian virus 40 lytic cycle. J. Virol. 17, 204-211 (1976)

Denis, H.: Accumulation du RNA dans les oocytes des vertébrés inférieurs. Biol. cellul. 28, 87-92 (1977) 
Elgin, S.C.R., Weintraub, H.: Chromosomal proteins and chromatin structure. Ann. Rev. Biochem. 44, 725-774 (1975)

Favre, M., Breitburd, F., Croissant, O., Orth, G.: Chromatin-like structures obtained after alkaline disruption of bovine and human papillomaviruses. J. Virol. 21, 1205-1209 (1977)

Finch, J.T., Klug, A.: Solenoidal model for superstructure in chromatin. Proc. nat. Acad. Sci. (Wash.) 73, 1897-1901 (1976)

Foe, V.E. : Modulation of ribosomal RNA synthesis in Oncopeltus fasciatus: An electron microscopic study of the relationship between changes in chromatin structure and transcriptional activity. Cold. Spr. Harb. Symp. quant. Biol. 42, 723-740 (1978)

Foe, V.E., Wilkinson, L.E., Laird, C.D.: Comparative organization of active transcription units in Oncopeltus fasciatus. Cell 9, 131-146 (1976)

Ford, P.J.: Ribonucleic acid synthesis during oogenesis in Xenopus laevis. In: Oogenesis (J.D. Biggers and A.W. Schuetz, eds.), pp. 167-191. Baltimore: University Park Press 1972

Franke, W.W., Scheer, U.: Structures and functions of the nuclear envelope. In: The cell nucleus (H. Busch, ed.), Vol. 1, pp. 219-347. New York: Academic Press 1974

Franke, W.W., Scheer, U., Spring, H., Trendelenburg, M.F., Zentgraf, H.: Organization of nucleolar chromatin. In: The cell nucleus (H. Busch, ed.), Vol. 7. New York: Academic Press (in press) 1978 a

Franke, W.W., Scheer, U., Trendelenburg, M.F., Spring, H., Zentgraf, H.: Absence of nucleosomes in transcriptionally active chromatin. Cytobiol. 13, 401-434 (1976)

Franke, W.W., Scheer, U., Trendelenburg, M.F., Zentgraf, H., Spring, H.: Morphology of transcriptionally active chromatin. Cold Spring Harb. Symp. quant. Biol. 42, 755-772 (1978b)

Gall, J.G., Rochaix, J.-D.: The amplified ribosomal DNA of dytiscid beetles. Proc. nat. Acad. Sci. (Wash.) 71, 1819-1823 (1974)

Griffith, J.D.: Chromatin structure: deduced from a minichromosome. Science 187, 1202-1203 (1975)

Hozier, J., Renz, M., Nehls, P.: The chromosomes fiber: evidence for an ordered superstructure of nculeosomes. Chromosoma (Berl.) 62, 301-317 (1977)

Keller, W., Müller, U., Eicken, I., Wendel, I., Zentgraf, H. : Biochemical and ultrastructural analysis of SV40 chromatin. Cold Spr. Harb. Symp. quant. Biol. 42, 227-244 (1978)

Kiryanov, G.I., Manamshjan, T.A., Polyakov, V.Yu., Fais, D., Chentsov, Ju.S. : Levels of granular organization of chromatin fibers. FEBS Letters 67, 323-327 (1976)

Klug, A.: Structure of chromatin. Introductory remarks. Phil. Trans. roy. Soc., London, B 283, 233-239 (1978)

Kornberg, R.D.: Structure of chromatin. Ann. Rev. Biochem. 46, 931-954 (1977)

Laird, C.D., Wilkinson, L.E., Foe, V.E., Choii, W.Y.: Analysis of chromatin-associated fiber arrays. Chromosoma (Berl.) 58, 169-190 (1976)

Lang, D., Mitani, M.: Simplified quantitative electron microscopy of biopolymers. Biopolymers 9, 373-379 (1970)

Li, H.J.: Chromatin subunits. In: Chromatin und chromosome structure (H.J. Li and R.A. Eckhardt, eds.), pp. 143-165. New York: Academic Press 1977

McKnight, S.L., Miller, O.L.: Electron microscopic analysis of chromatin replication in the cellular blastoderm of the Drosophila melanogaster embryo. Cell 12, 795-804 (1977)

Miller, O.L., Bakken, A.H.: Morphological studies of transcription. Acta endocrinol., Suppl., 168, 155-177 (1972)

Müller, U., Zentgraf, H., Eicken, I., Keller, W. : Higher-order structure of Simian virus 40 chromatin. Science 201, 406-415 (1978)

Oudet, P., Germond, J.E., Bellard, M., Spadafora, C., Chambon, P. : Nucleosome structure. Phil. Trans. roy. Soc. London B 283, 241-258 (1978)

Oudet, P., Gross-Bellard, M., Chambon, P.: Electron microscopic and biochemical evidence that chromatin structure is a repeating unit. Cell 4, 281-300 (1975)

Pinon, H., Barat, M., Tourte, M., Dufresne, C., Mounolou, J.C.: Evidence for a mitochondrial chromosome in Xenopus laevis oocytes. Chromosoma (Berl.) 65, 383-389 (1978)

Popenkov, V.I., Vengerov, Yu.Yu.: The effect of various conditions of chromatin isolation on the nucleosomal structure of the isolated chromatin. Molec. Biol. Rep. 4, 45-50 (1978)

Renz, M., Nehls, P., Hozier, J.: Involvement of histone H1 in the organization of the chromosome fiber. Proc. nat. Acad. Sci. (Wash.) 74, 1879-1883 (1977) 
Scheer, U.: Changes of nucleosome frequency in nucleolar and non-nucleolar chromatin as a function of transcription: an electron microscopic study. Cell 13, 535-549 (1978)

Scheer, U., Trendelenburg, M.F., Franke, W.W.: Effects of actinomycin D on the association of newly formed ribonucleoproteins with the cistrons of ribosomal RNA in Triturus oocytes. J. Cell Biol. 65, 163-179 (1975)

Scheer, U., Trendelenburg, M.F., Franke, W.W.: Regulation of transcription of genes of ribosomal RNA during amphibian oogenesis. J. Cell Biol. 69, 465-489 (1976)

Scheer, U., Trendelenburg, M.F., Krohne, G., Franke, W.W.: Lengths and patterns of transcriptional units in the amplified nucleoli of oocytes of Xenopus laevis. Chromosoma (Berl.) 60, $147-167$ (1977)

Trendelenburg, M.F.: Morphology of ribosomal RNA cistrons in oocytes of the water beetle, Dytiscus marginalis L. Chromosoma (Berl.) 48, 119-135 (1974)

Trendelenburg, M.F., Franke, W.W., Scheer, U.: Frequencies of circular units of nucleolar DNA in oocytes of two insects, Acheta domesticus and Dytiscus marginalis, and changes of nucleolar morphology during oogenesis. Differentiation 7, 133-158 (1977)

Trendelenburg, M.F., Scheer, U., Zentgraf, H., Franke, W.W.: Heterogeneity of spacer lengths in circles of amplified ribosomal DNA of two insect species, Dytiscus marginalis and Acheta domesticus. J. molec. Biol. 108, 453-470 (1976)

Trendelenburg, M.F., Zentgraf, H., Franke, W.W., Gurdon, J.B.: Transcription patterns of amplified Dytiscus genes coding for ribosomal RNA after injection into Xenopus oocyte nuclei. Proc. nat. Acad. Sci. (Wash.) 75, 3791-3795 (1978)

Worcel, A., Benyajati, C.: Higher order coiling of DNA in chromatin. Cell 12, 83-100 (1977)

Zentgraf, H., Falk, H., Franke, W.W.: Nuclear membranes and plasma membranes from hen erythrocytes. IV. Characterization of nuclear membrane attached DNA. Cytobiol. 11, 10-29 (1975)

Zentgraf, H., Keller, W., Müller, U.: The structure of SV40 chromatin. Phil. Trans. roy. Soc., London, B 283, 299-303 (1978)

Received and accepted July 28,1978 by J.G. Gall

Ready for press August 16, 1978 